\title{
Parametric Study of Experimental and Numerical Simulation of Sandwich Composite Structures Flexural Behaviour
}

\author{
ELENA FELICIA BEZNEA*, IONEL CHIRICA, NICUSOR BAROIU, VIRGIL TEODOR \\ Dunarea de J os University of Galati, 47 Domneasca Str., 800008, Galati, Romania
}

\begin{abstract}
Sandwich panels with composite/steel skin sheets and foam core are very often used as lightweightstructures in automotive, maritime and aerospace applications due to their performances like high bending stiffness and strength and also lightweight. As an alternative to classical structural reinforced panels, the sandwich structures are justifying their use in various industrial fields, making these structures less complex, by eliminating the need for secondary stiffening. In the paper are presented three models of sandwich, steelfoam-steel, composite-foam-composite or steel-foam-composite structures, of different thicknesses, with functional use in various fields depending on necessities. The mechanical characteristics of the materials used in their manufacture have been determined. The panels have been subjected to various load cases in order to determine an optimal combination of weight and strength. At the same time, the numerical models used in the finite element analysis of the sandwich structures with specific elements for layered composites or sandwich (SHELL 4L and SOLID L) are presented.
\end{abstract}

Keywords: sandwich composites, composite mechanical tests, FEM modeling

Sandwich structures are a particular case of laminated composite material, which consists of a relatively thick and soft middle layer (core) located between thin, rigid and strong skins. The skins are usually made of metallic material, polymer-based composites, or combination of these materials while the core may be a polymeric foam, a honeycomb or other material [1] that has the role of keeping the skins away, to achieve the proposed strength and rigidity performances of the panel. The main advantage of the core is that it is light, but has a great contribution to the panel's strength and stiffness. Considering the strengthto-weight ratio, simplicity in construction, and impact strength properties, such a structure, called the Sandwich Plate System (SPS), is widely used in most industrial areas, [2-5].

The performance of FEM simulations of sandwich plates and accurate descriptions of the flexural behaviour, require the modeling of both the skins as well as the core.

The transfer of load between the constituent elements is achieved by bonding the faces and the core, which leads to the obtaining of a new material, with high stiffness and high strength but with a very low weight, by 10 to $70 \%$ versus metal structure [2], with consequences of reducing operational construction costs compared to equivalent steel structures.

Generally, for SPS production in the field of ship structures, thicknesses of 1-8 $\mathrm{mm}$ for metal faces and 15$50 \mathrm{~mm}$ for core are used, which does not modify structural resistance and safety in comparison with a similar steel model. In situations of intentional or accidental loading, including due to collision impact or wave shock, a welldesigned SPS structure can withstand much larger impulses than a solid structure of the same weight [6].

SPS panels are very stable due to the core that prevents the effects of local buckling. Semi-empirical equations have been developed to determine the load capacity and these have been verified using complete static or dynamic (DMA) tests [7-10], but also by finite element analysis [1112]. In general, the structural analysis with finite elements of composite sandwich structures is performed in order to determine the equivalent stresses and to observe the total

\footnotetext{
* email: elena.beznea@ugal.ro; Phone: 0743605440
}

deformations for different constructive solutions. In a SPS composite structure, the equivalent stresses as well as the total deformations suffer variations depending on the nature of the face material, the core and the thickness of the layers, correlated with their dimensional values, but also depending on the mode of application of the loads [13-16].

In the paper is presented a comparative analysis of the finite element of three sandwich plate systems, with skins' thicknesses of 1,2 and $3 \mathrm{~mm}$ respectively, made out of a polymer (polyester resin and bidirectional fiber glass fabric) / steel and a $18 \mathrm{~mm}$ thick core, made out of polyurethane foam (extruded polystyrene foam). The various combinations of material types have been used: steelfoam-steel composites, composite-foam-composite and steel-foam-composite, for which the mechanical characteristics have been previously determined.

\section{Experimental part}

Mechanical tests

Core mechanical characteristics estimation

A specimen having dimensions of $I_{x}=I_{x}=I_{z}=100 \mathrm{~mm}$, made out of foam used for core fabrication hăs been tested to estimate the mechanical characteristics (fig. 1).

The compression test has been performed by loading the specimen with axial force having values from 0 to $5 \mathrm{kN}$, only for elastic range. In thefigure 2 the stress-strain curve is illustrated. As it is seen, the characteristic curve is linear in the elastic domain $[17,18]$. According to the test, the mechanical characteristics obtained for foam are: Young's

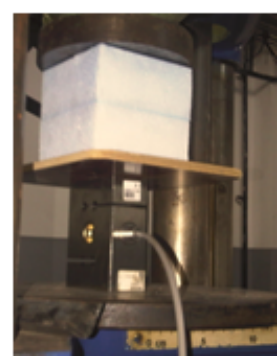

Fig. 1 Compression test for core material

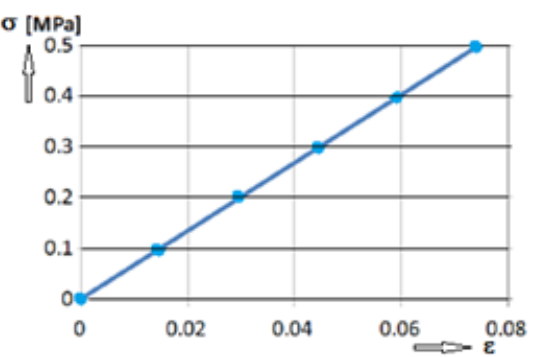

Fig. 2 Stress-strain curve for core's material 
modulus $\mathrm{E}=0.67 \mathrm{MPa}$, Poisson's ratio $\mu=0.011$, shear modulus, $\mathrm{G}=0.33 \mathrm{MPa}$.

Skin's polymer mechanical characteristics estimation

For skins, the polymer (polyester resin and bidirectional fiber glass fabric) has been used. The mechanical characteristics have been determined a specimen having dimensions of $250 \times 25 \times 5 \mathrm{~mm}$. The tensions test has been performed by loading the specimen with axial force (fig. 3). In figure 4 the stress-strain curve is illustrated. As it is seen, the characteristic curve is linear in the elastic domain.

According to the test, the mechanical characteristics obtained for foam are: Young's modulus Ex $=38.6 \mathrm{GPa}$, $E y=8.27 \mathrm{GPa}$, Poisson's ratio $\mu=0.26$, shear modulus, $\mathrm{G}=4.14 \mathrm{GPa}$.
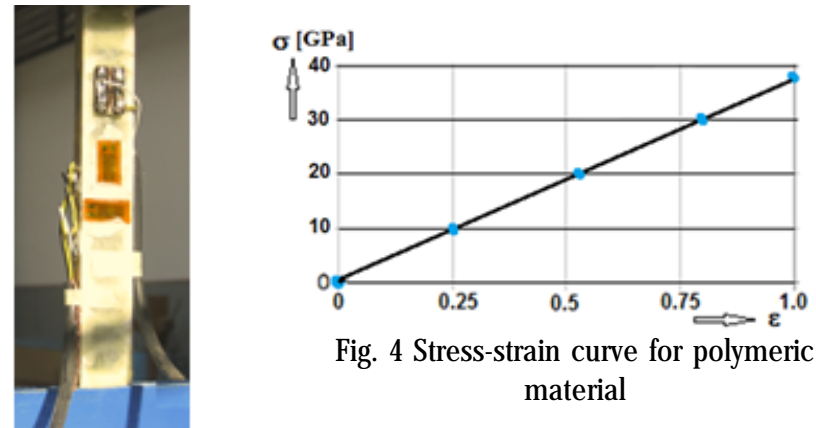

Fig. 4 Stress-strain curve for polymeric material

Fig. 3 Tensile test for polymeric material

Skin's steel mechanical characteristics

Since the mechanical characteristics of the steel are generally known, they have not been determined experimentally, taking the ones known in the literature.
Numerical parametric analysis of the flexural characteristics of the sandwich composite panels

Numerical analysis was performed on sandwich structural composite plates, simply supported on two sides at $10 \mathrm{~mm}$ from the short sides. Loading was done with uniformly distributed pressure on a rectangular area of $100 \mathrm{~mm} \times 20 \mathrm{~mm}$ on the middle of the plate surface. The resultants of the three pressure cases are: $\mathrm{P} 1=27.7 \mathrm{~N}$; P2 $=36.6 \mathrm{~N} ; \mathrm{P3}=45.5 \mathrm{~N}$.

The COSMOS/M licensed code has been used to determine the stiffness and strength characteristics of sandwich structural composite plates. Two FEM models have been used: SHELL4L and SOLIDL. In figures 5 and 6 the mesh using the two FE models are illustrated.

The displacements maps $\left(w_{-}[\mathrm{mm}]\right)$, for the three loading cases, in the case of thickness of $1 \mathrm{~mm}$ are illustrated in tables 1 and 2 for the both FE mesh models.
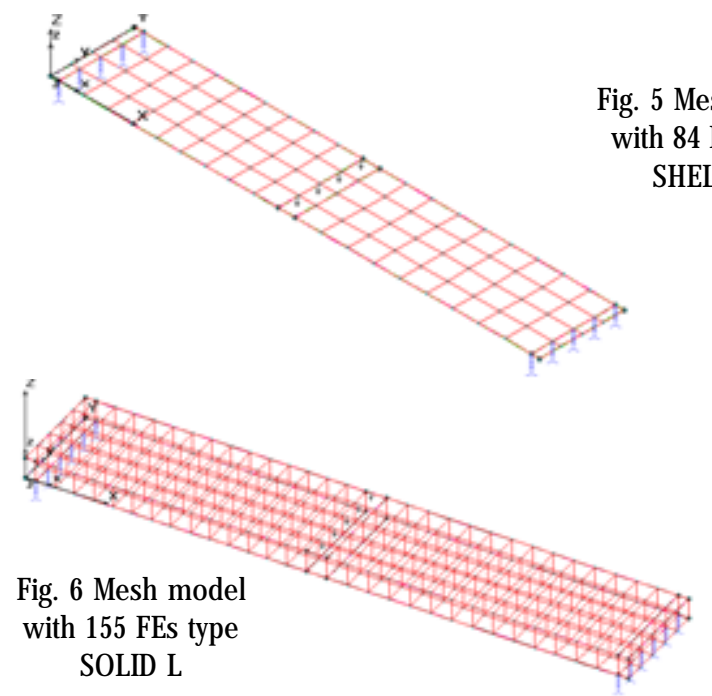

Fig. 5 Mesh model with 84 FEs type SHELL 4L

Table 1

DISPLACEMENTS MAPS FOR SHELL 4L MESH MODEL

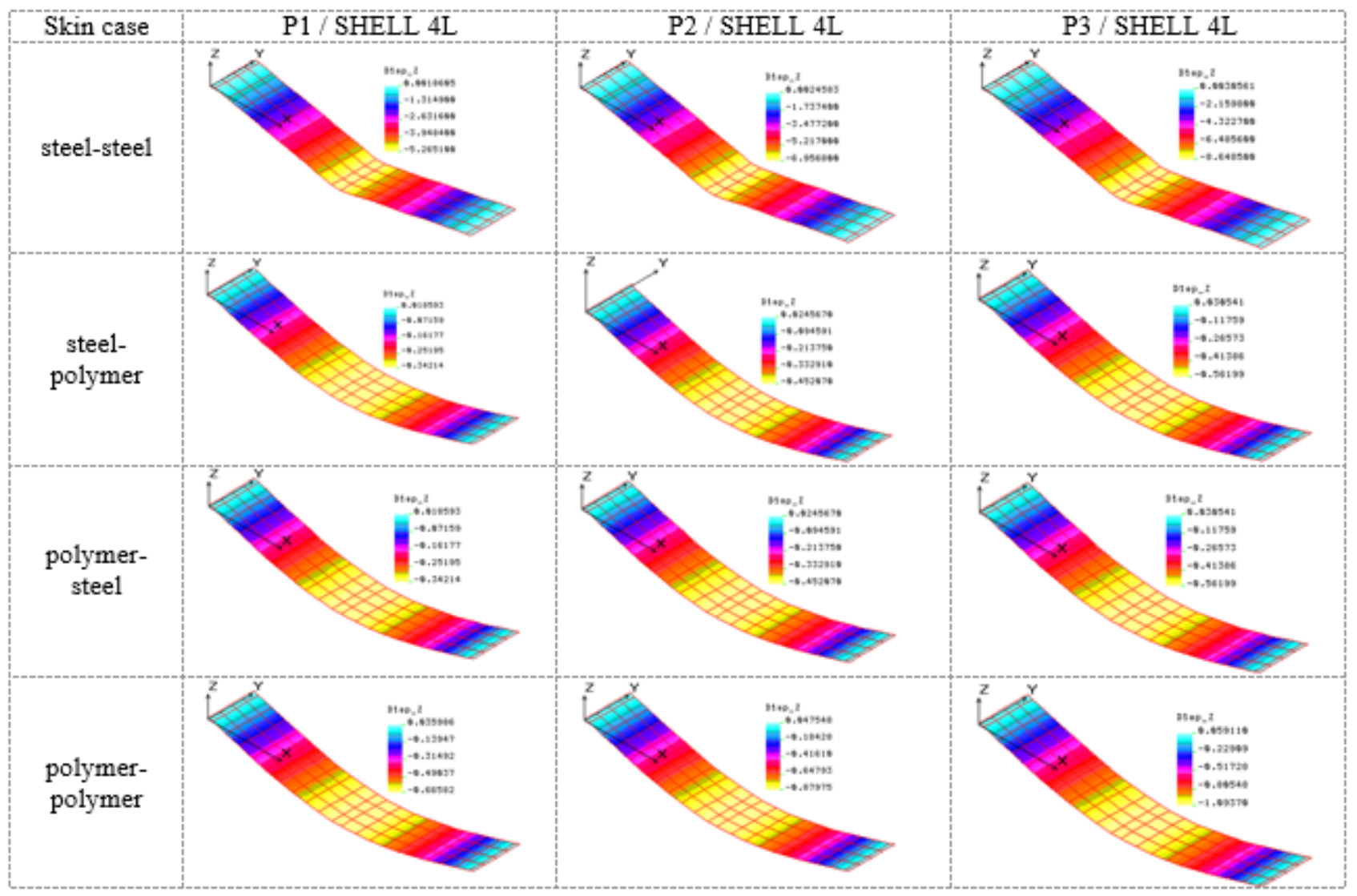


Table 2

DISPLACEMENTS MAPS FOR SOLID L MESH MODEL

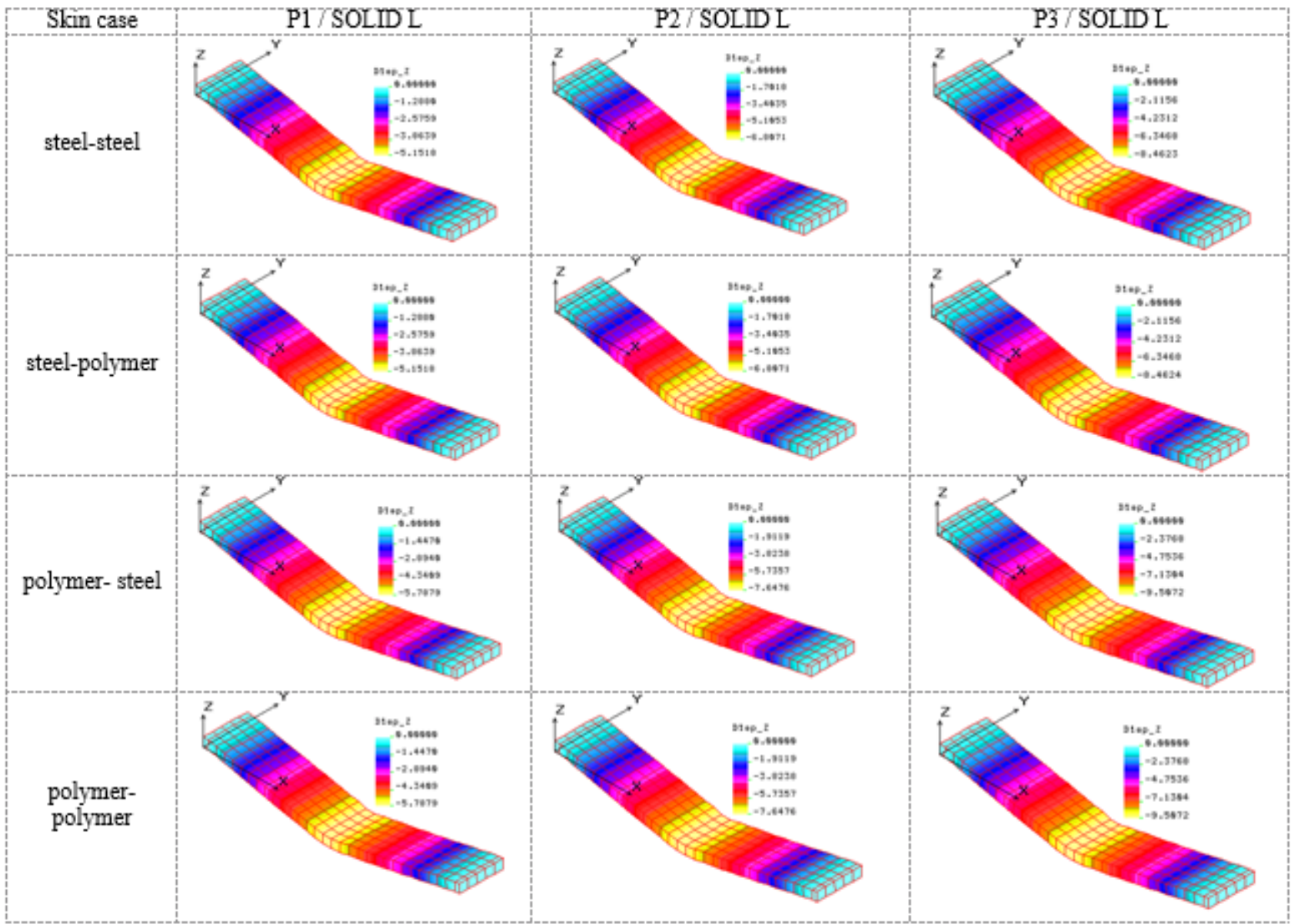

According to the results obtained in numerical analysis, the variation of the maximum displacement obtained for the all skin cases and the three skin thickness values, for the both FE models, in loading case P1 are presented in figure 7 . As it is expected, the panels with the faces made out of steel are more stiffen.

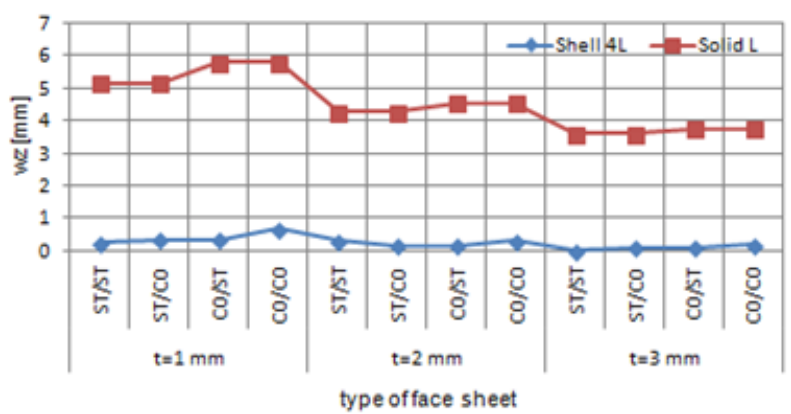

Fig. 7 Variation of the panels' maximum displacements for loading case P1

In figures 8 and 9 , the variation of the maximum displacement versus the loading case for all three skin's thickness values, for each combination of skin materials are illustrated. As it is expected, the maximum displacement values are increasing since the skin's thickness is decreasing. The difference in modeling with the two FE models is observed. The modeling with SOLID $L$ produces an elastic structure compared with the modeling with SHELL 4L.

For the most critical point of the panel, the variation of the normal stress and shear stress on the thickness are drawn [19]. In the figures 10 and 11these variation are illustrated for the both modeling cases: SHELL 4L and SOLID L.
As it is seen in figures 10 and 11 the variation of stresses for modeling with SHELL 4L and SOLID L elements produces differences in variation within the thickness.

The actual shear stresses distribution is parabolic through the thickness of the face and core. In the case the faces are much thinner and stiffer than the core (as, indeed, they always are) then the shear stress can be treated as linear through the face and constant in the core.

\section{Experimental part}

Sandwich panels with the structure and dimensions described in previous chapter have been fabricated (fig. 12). The 9 panels have been tested in the situation of three points bending like the composite beams (Three points bending test simulation). In order to determine the states of stress and displacements in plates, a rig concerning the following equipment have been used: predefined weights, displacement transducer; strain gauges; Quantum strain gauge bridge; Laptop and Catman data acquisition and processing software.

In table 3 the characteristics of the manufactured sandwich plates used for three points bending test simulation are described.

The plates have been supported on lines parallel to the short sides at a distance of $10 \mathrm{~mm}$ from the side. The loading of each of the plates was done with 3 forces. Each plate was loaded, sequentially with the predefined weights (P1, P2 and P3). The displacement from the middle section of the plate (for all plates) was recorded with LVDT system (fig. 13).

In figure 14 the variation of the maximum displacement versus the skin's thickness for loading case P1 for each combination of skin materials so for numerical and experimental analysis are illustrated. As it is expected, the 


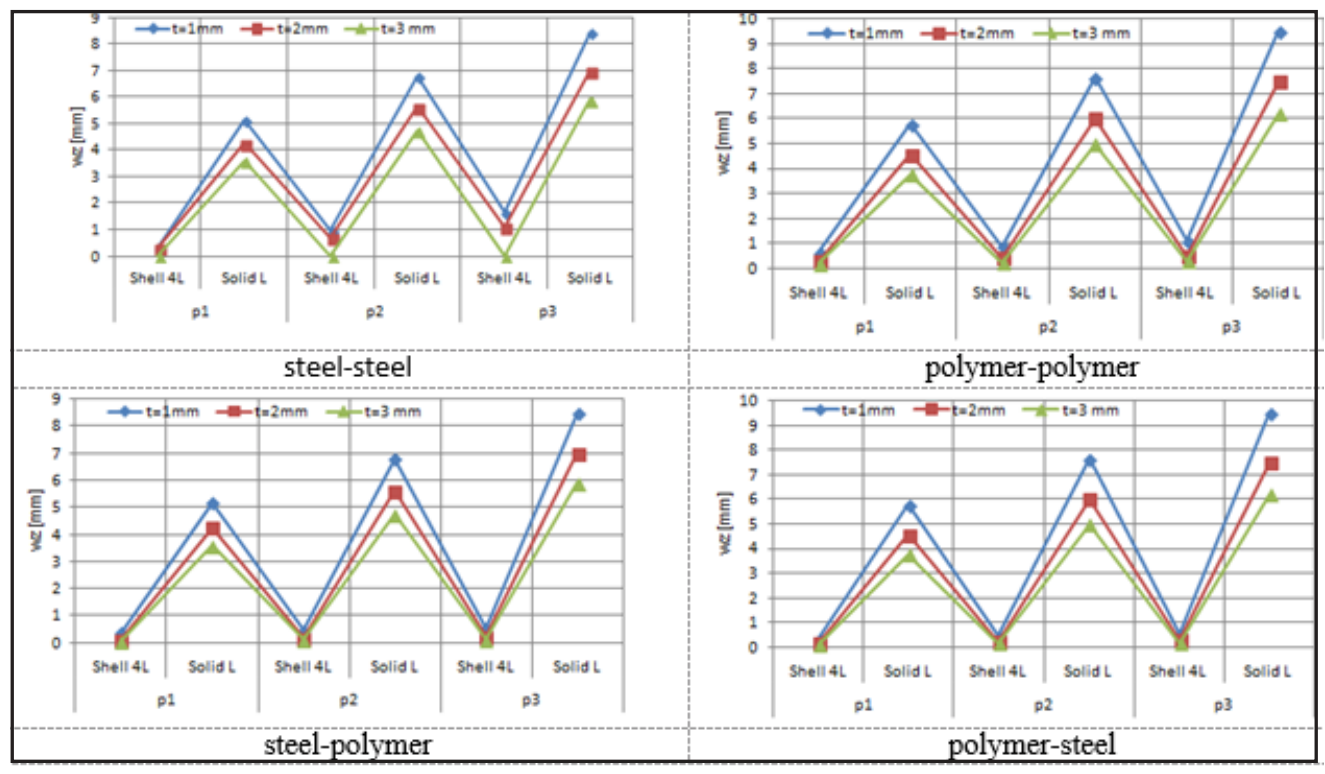

Fig. 8 Thickness variation [mm] versus the loading case

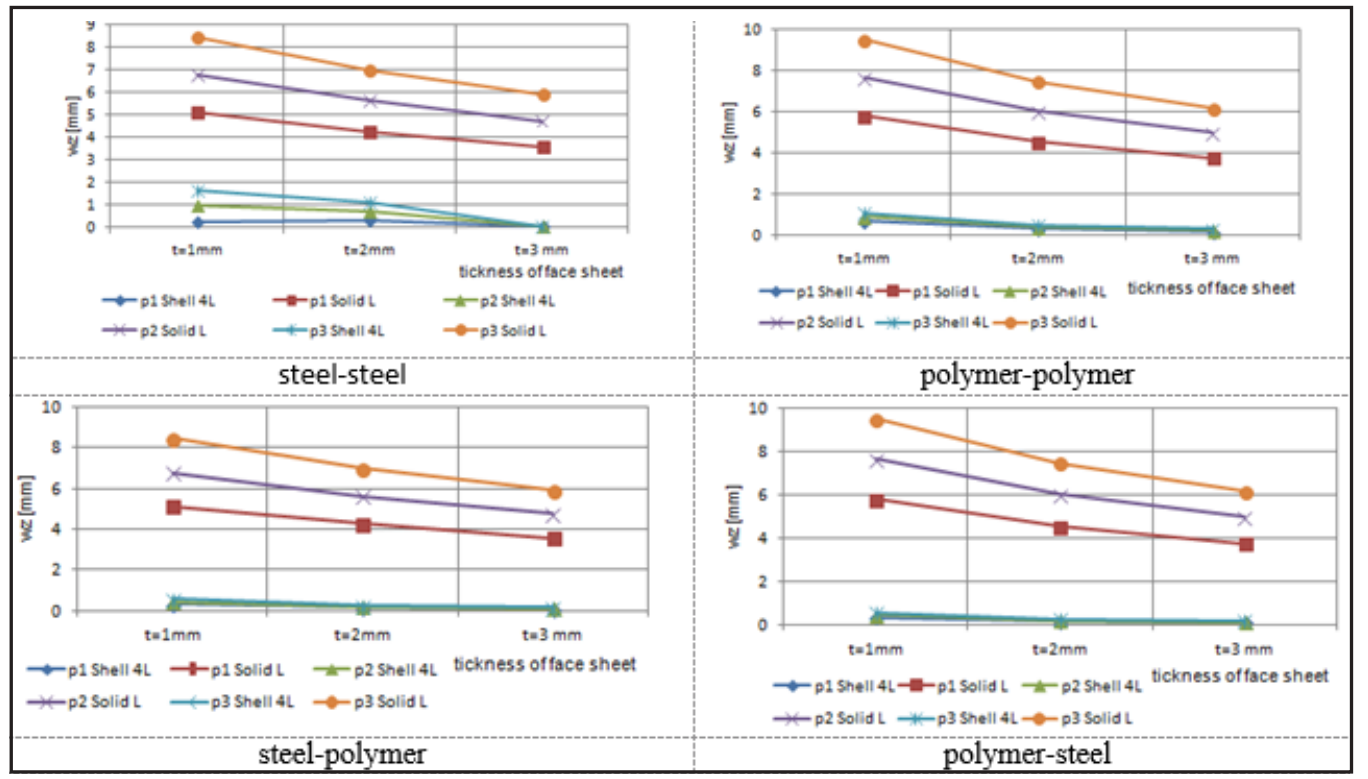

Fig. 9 Thickness variation [mm] versus the skin's thickness

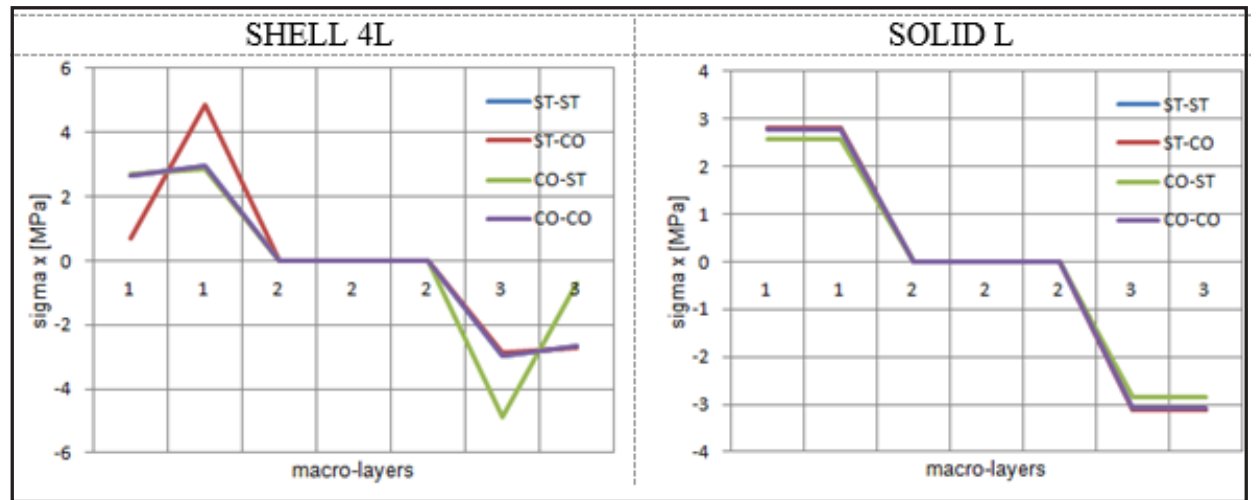

Fig. 10 Normal stress variation along thickness for loading case P3 and skin thickness of $1 \mathrm{~mm}$

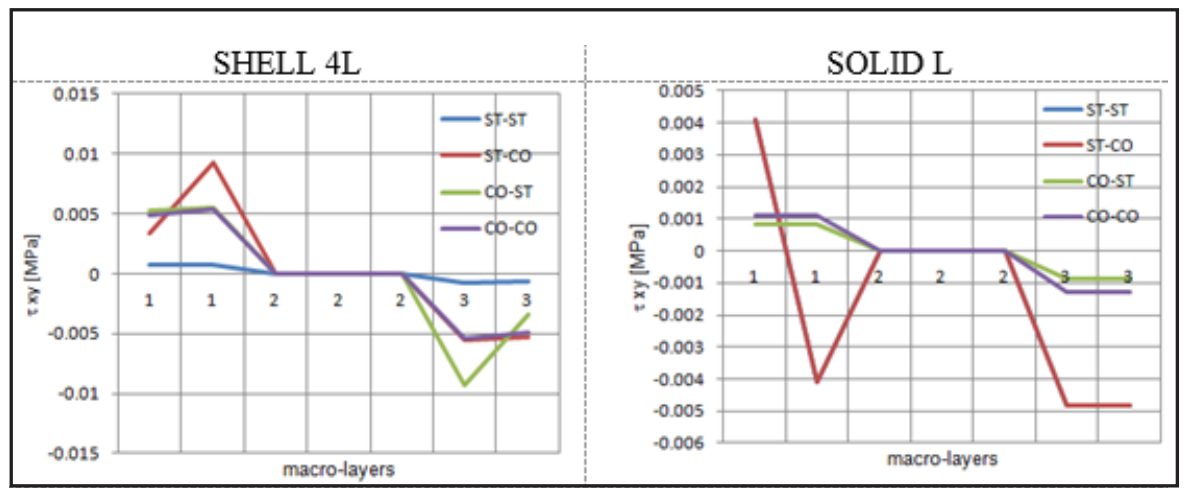

Fig. 11 Shear stress variation along thickness for loading case P3 and skin thickness of $1 \mathrm{~mm}$ 


\begin{tabular}{|c|c|c|c|c|c|}
\hline \multirow{2}{*}{ No. } & \multicolumn{5}{|c|}{ Sandwich type } \\
\cline { 2 - 6 } & \multicolumn{2}{|c|}{ Face 1 } & Core & \multicolumn{2}{c|}{ Face 2 } \\
\cline { 2 - 7 } & thickness [mm] & material & thickness[mm]/material & thickness [mm] & material \\
\hline 1 & 1 & steel & $18 /$ polistiren & 1 & steel \\
\hline 2 & 1 & steel & $18 /$ polistiren & 1 & polymer \\
\hline 3 & 1 & polymer & $18 /$ polistiren & 1 & polymer \\
\hline 4 & 2 & steel & $18 /$ polistiren & 2 & steel \\
\hline 5 & 2 & steel & $18 /$ polistiren & 1 & polymer \\
\hline 6 & 2 & polymer & $18 /$ polistiren & 2 & polymer \\
\hline 7 & 3 & steel & $18 /$ polistiren & 3 & steel \\
\hline 8 & 3 & steel & $18 /$ polistiren & 1 & polymer \\
\hline 9 & 3 & polymer & $18 /$ polistiren & 3 & polymer \\
\hline
\end{tabular}

Table 3

PLATES

CHARACTERISTICS

Fig. 12 The manufactured sandwich plates
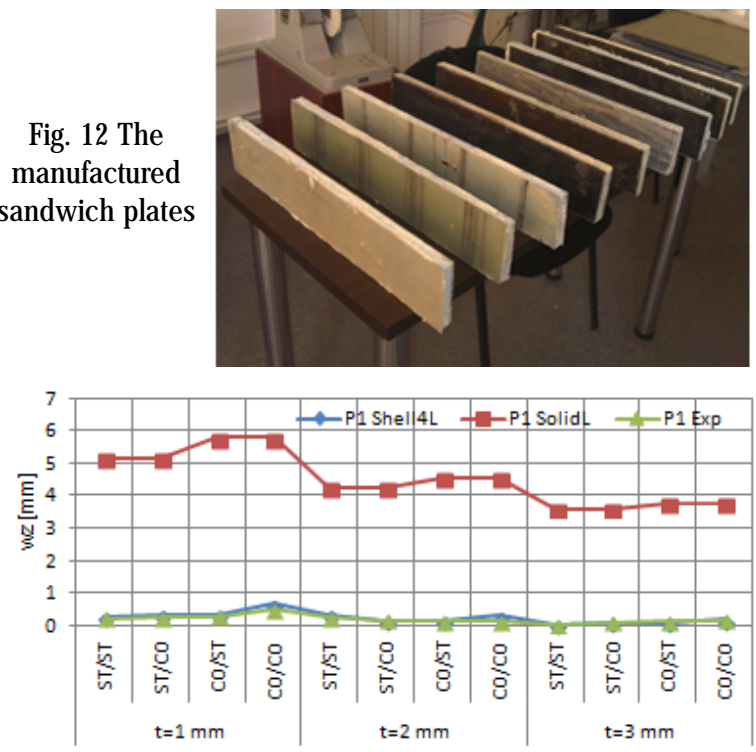

type of face sheet

Fig. 14 Variation of maximum displacement in the three cases (experimental and numerical: modeling with SHELL $4 \mathrm{~L}$ and SOLID $L$ elements) for $P 1$

maximum displacement values are increasing since the skin's thickness is decreasing. In figure 15 the variation of maximum displacement in the three cases (experiment and numeric modeling with SHELL 4L and SOLID L elements) for the cases of P1 loading and P2 loading.

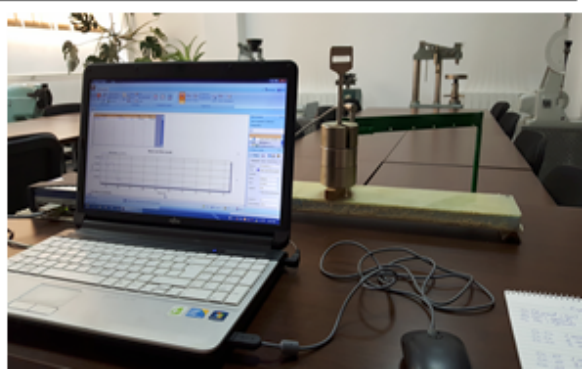

Fig. 13 Experimental test

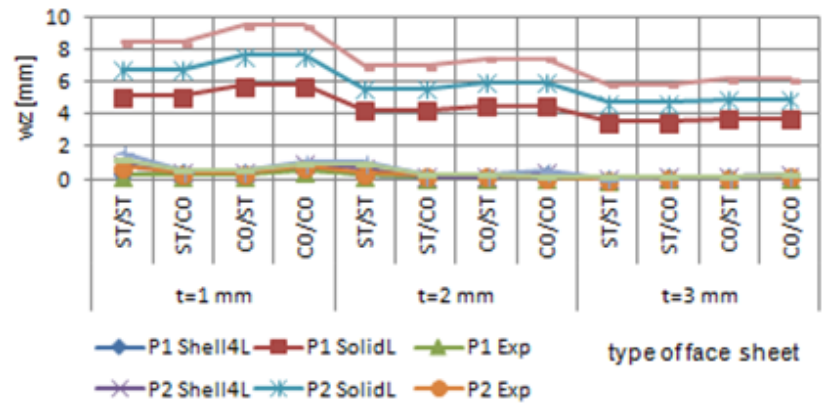

Fig 15 Variation of maximum displacement in the three cases (experimental and numerical: modeling with SHELL 4 L and SOLID $L$ elements) for P1 and P2

The difference in modeling with the two FE models is observed. The modeling with SOLID L produces an elastic structure compared with the modeling with SHELL 4L.

As can be seen from the graphical representation in the figure 15, the maximum displacement value for SHELL 4L modeling is approximately the same as in the experimental
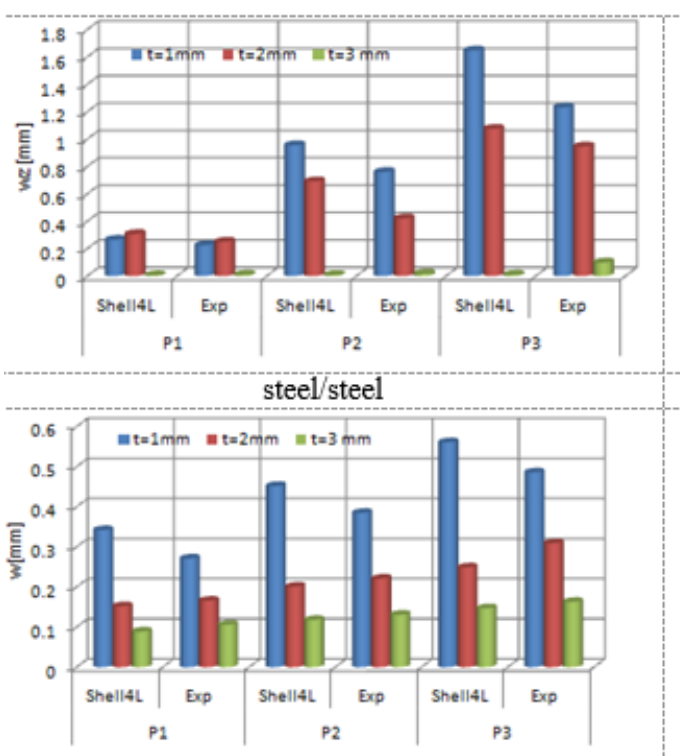

steel/polymer

(1)

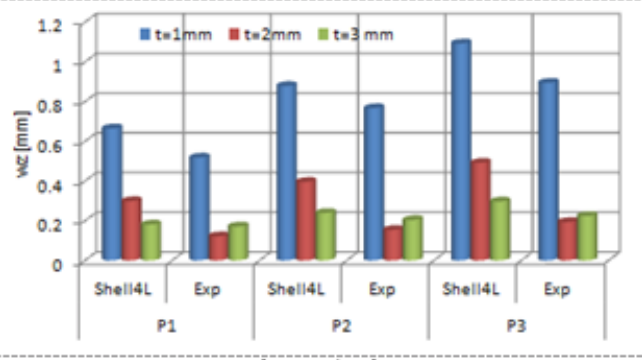

polymer/polymer

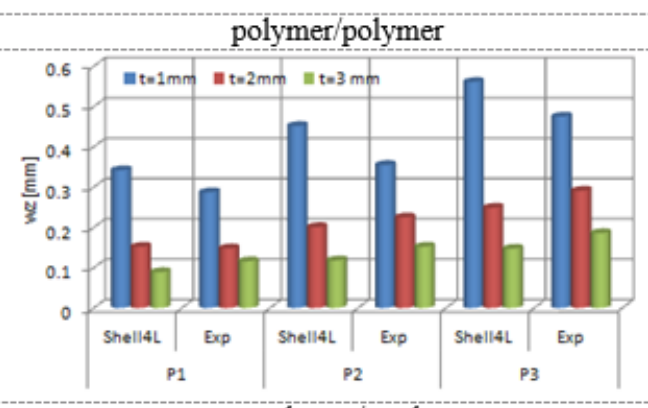

polymer/steel

http://www.revmaterialeplastice.ro
Fig. 16 Variation of the maximum displacement [ $\mathrm{mm}$ ] versus the three loading cases
MATERIALE PLASTICE $\bullet 54$ No. 4 • 2017 

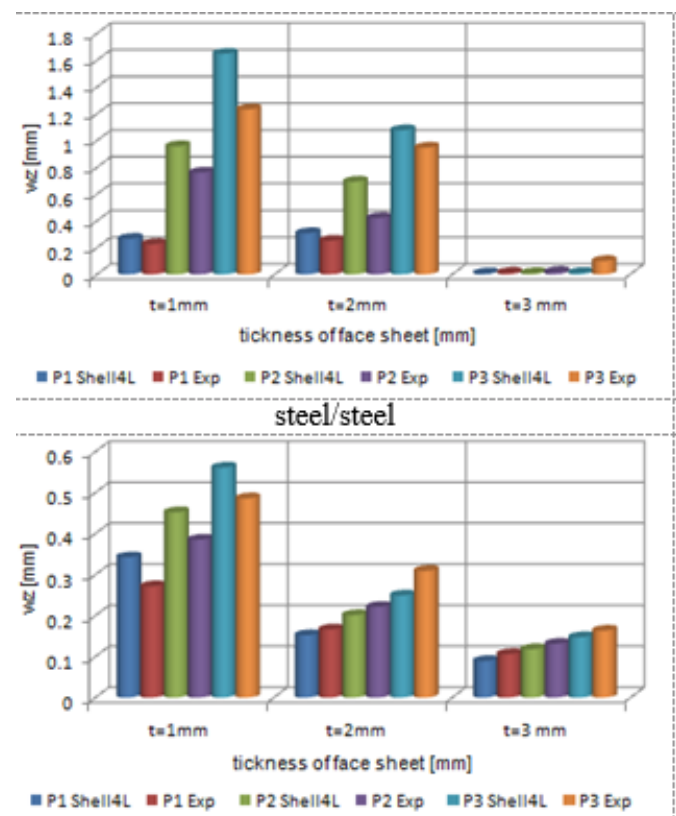
steel/polymer

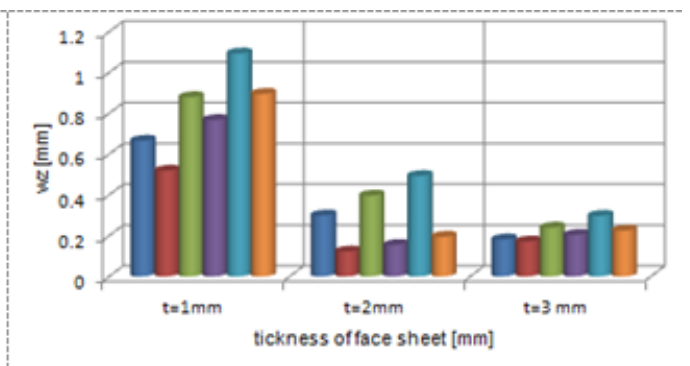

=P1 Shell4L $=P 1$ Exp $=P 2$ Shell4L $=P 2 \operatorname{Exp} \quad=P 3$ Shell4L $=P 3 \operatorname{Exp}$ polymer/polymer

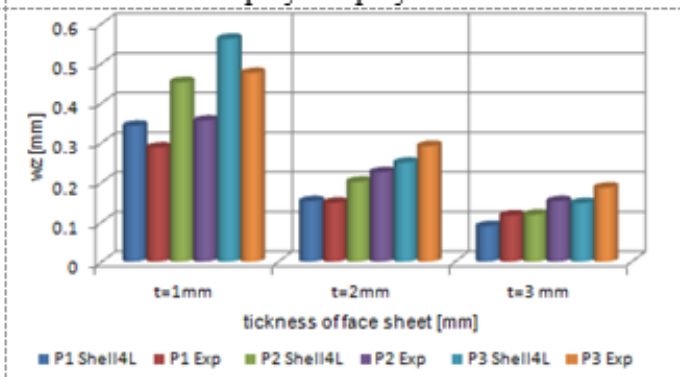

polymer/steel
Fig. 17 Variation of the maximum displacement [ $\mathrm{mm}]$ versus the skin thickness case. When modeling with SOLID L elements, the values are about $15 \%$ higher than the experimental values for displacements.

As a final conclusion, in figures 16 and 17 the variation of the maximum displacement versus the three loading cases and skin thickness for the experiment analysis and modeling with SHELL 4L (best numerical model) are illustrated.

Following the analysis with finite elements (SHELL 4L modeling) and following the experimental measurements, the following conclusions can be drawn:

- The maximum displacement increases directly proportional to the load in all the cases analyzed both in modeling and experimentation;

- The maximum displacement decreases as the thickness of the faces increases, regardless of their material.

- By analyzing the graphs it can be observed that the displacement value is approximately the same for both SHELL 4L modeling and experimental measurements.

\section{Conclusions}

The flexural behaviour of composite sandwich panels has been numerical and experimental modeled by performing a 3D finite element static three points bending test simulation. The foam core and the face sheets have been modeled using two FE models: SHELL 4L and SOLID $L$. The accuracy of the FE model was evaluated by comparing experimental results with numerical predictions for various loading and various thicknesses of the face sheets. The agreement with the experimental results was satisfactory for the model with SHELL 4L in the case of displacements variation. In addition, it was found that the variation of the normal and shear stresses within the thickness has the leap on the interface between skins and core. The convergence study performed during analysis showed that the results are converging with mesh refinement.

The differences between the numerical and experimental values are within the expected range. The parametric study shows that the central deflection of the panel increases since the face sheets thickness decreases.
Acknowledgment: This work was supported by a grant of the Romanian National Authority for Scientific Research and Innovation, CNCS UEFISCDI, project number PN-II-RU-TE-2014-4-0031

\section{References}

1. VINSON J.R., Sandwich structures: past, present, and future Sandwich Structures 7: Advancing with Sandwich Structures and Materials, Springer, Dordrecht, pp. 3-12, ISBN 978-1-4020-3444-2, 2005. 2. RAMAKRISHNAN K.V., SUNIL KUMAR G., Applications of Sandwich Plate System for Ship Structures, IOSR J ournal of Mechanical and Civil Engineering (IOSR-J MCE), pp. 83-90, ISSN: 2320-334X, 2016.

3. MOMCILOVIC N., MOTOK M., Estimation of Ship Lightweight Reduction by Means of Application of Sandwich Plate System, FME Transactions Vol. 37, No 3, pp. 123-128, 2009.

4. KOZAK J., Selected problems on application of steel sandwich panels to marine structures, Polish Maritime Research 4(62), Vol. 16, pp. 9-15, 2009.

5. MA S., Studies of Composite Multihull Ship Structures Using Fluid Structure Interaction, Faculty of College of Engineering and Computer Science, Dissertation, Florida Atlantic University, 2012.

6. XUE Z., HUTCHINSON J.W., A comparative study of impulse-resistant metal sandwich plates, International J ournal of Impact Engineering, Vol. 30, pp. 1283-1305, 2004.

7. PIOVAR S., KORMANIKOVA E., Statical and Dynamical Analysis of Composite Sandwich Plates, Bulletin of the Transilvania University of Braov, Series I: Engineering Sciences, Vol. 4 (53), pp. 177-184, 2011. 8. ANDENA L., MANCONI E., MANZONI S., MOSCHINI S., VANALI M., Experimental tests and numerical modeling of a sandwich panel, Proceedings of the $25^{\text {th }}$ International Conference on Noise and Vibration engineering (ISMA), Leuven, Belgium, pp. 1841-1851, 2012. 9.YUNGWIRTH C.J ., WADLEY H.N.G., O'CONNOR J.H., Impact response of sandwich plates with a pyramidal lattice core, International J ournal of Impact Engineering, Vol. 35, pp. 920-936, 2008.

10. VAMJA D.G., TEJANI G.G., Experimental Test on Sandwich Panel Composite Material, International Journal of Innovative Research in Science, Engineering and Technology, Vol. 2, Issue 7, ISSN: 2319-8753, pp. 3047-3054, 2013.

11.CHIRICA I., BEZNEA E.F., GAVRILESCU I., Metode moderne de calcul al structurilor compozite, Ed. Cermi, Iasi, ISBN 978-973-667283-5, 2007.

12. TABACU, ST., HADAR, A., MARINESCU,D., MARIN,D., DINU,G., SMARANDA IONESCU, D., Mat. Plast., 45, no.1,2008, p.113. 
13. GOPICHAND A., KRISHNAIAH G., REDDY D., SHANKAR V.S., Modal Analysis of a Steel Sandwich Plate System (SPS) Floor, International Journal of Engineering Research \& Technology (IJ ERT), Vol. 2, Issue 11, pp. 3002-3004, 2013.

14. KOVACS G., SZIRBIK S., Verification of an Optimal Composite Sandwich Structure by Finite Element Analysis, Annals of Faculty Engineering Hunedoara - International J ournal of Engineering, Tome X, Fascicle 3, ISSN 1584-2673, pp. 395-398, 2012.

15. CERBU, C., CURTU, I., Mat. Plast., 48, no.1,2011, p. 93

16. BAGADI G.K., RAMBABU S.B., Design and Analysis of Stainless Steel and Mild Steel Sandwich Composite Structure, International
Journal \& Magazine of Engineering, Technology, Management and Research, Vol. 2, Issue 4, ISSN: 2348-4845, pp. 624-632, 2015.

17. BRIA, V., CIRCIUMARU, A., BIRSAN, I.G., Mat. Plast., 48, no.2, 2011, p. 189

18. GOANTA, V., HADAR, A., LEITOIU, B., Mat. Plast., 47, no. 4, 2010, p. 450 ,

19. SZEKRENYES A., Interface fracture in orthotropic composite plates using second-order shear deformation theory, International Journal of Damage Mechanics, March 12, 2013

Manuscript received: 8.08.2017 